\title{
Identification of hydro-acoustic waves emitted from floating units during mooring tests
}

\author{
Eugeniusz Kozaczka, \\ Gdansk University of Technology \\ Jacek Domagalski, Grażyna Grelowska, Ignacy Gloza \\ Naval University of Gdynia
}

\begin{abstract}
Measurements of hydro-acoustic noise emitted from vessels are a.o. a subject of the tests carried out in the control measurement ranges of the Navy. The measurements are performed both on anchored and floating vessels. Acoustic field of vessels is changing along with their speed changing and is associated with acoustic activity of wave sources installed in vessel's hull (main engines, electric generating sets, reduction gears, pumps, shaft-lines, piping, ventilating ducts etc) as well as hydro-dynamic sources such as screw propellers and water flow around the hull [5, 7]. Vibration energy generated by the onboard devices is transferred through ship structural elements to water where it propagates in the form of hydro-acoustic waves of a wide frequency band.
\end{abstract}

Keywords: identification, propagation, hydro-acoustics

\section{INTRODUCTION}

Identification of sources of underwater noise generated by moving vessel in which various devices are installed, is a complex problem $[2,3,4,6]$. Vibration energy propagating through ship structural elements interfers with acoustic waves emitted by various sources, that additionally complicates their identification.

One of the methods for identifying ship - generated underwater noise is examination of its spectrum. On the basis of such investigations can be selected characteristic components of the spectrum associated with running ship's mechanisms and devices as well as continuous spectrum which reflects work of cavitating ship propeller, turbulent flow in piping systems, fans, friction in slide bearings etc. It is rather hard to practically identify underwater noise. Ship-borne noise is mixed with environmental technical noise propagating from remote ships, shipbuilding and port facilities. There are also natural noise sources such as waves, wind and rain.

An additional difficulty in identifying acoustic spectrum components may be that various shipboard devices may emit waves of similar of identical frequencies.

This paper presents results of identification tests of a ship on the basis of measurements of underwater noise and vibration of main engines and electric generating sets, recorded in main and auxiliary engine rooms. The tests were carried out in two phases. In the first phase, mooring tests of the ship were performed. They consisted of simultaneous measurements of vibrations recorded on board and acoustic pressure - in water depths. After that cycle of the tests ship measurements were carried out on a dynamic testing range. Their results will be published later.

\section{MOORING TESTS OF THE SHIP}

The measurements were carried out in Gdańsk Bay waters in the area free from disturbances generated by marine industry, merchant and naval ports and fairways. Schematic diagram of the testing range is presented in Fig. 1.

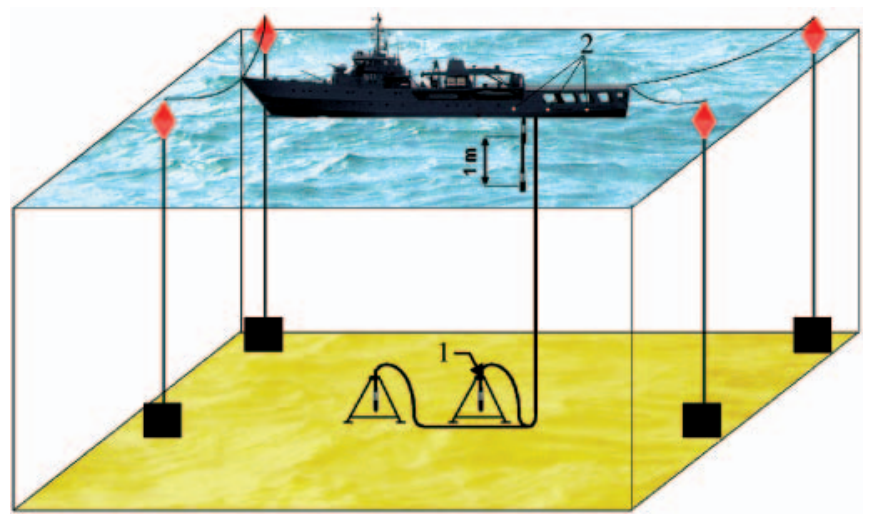

Fig. 1. Schematic diagram of the testing range for moored ship's investigations. Notation: 1 - hydrophones, 2 - accelerometers.

The investigation was aimed at selecting characteristic components of the spectrum, associated with work of particular ship machines and devices. Frequencies of the components were determined by comparing spectral density of vibration 
power and that of underwater noise. To this end was used the coherence function which - for two signals : $v(t)$ and $p(t)$ - is defined as follows $[1,2]$ :

$$
\gamma_{\mathrm{pv}}^{2}\left(\mathrm{f}_{\mathrm{k}}\right)=\frac{\left|\mathrm{G}_{\mathrm{pv}}\left(\mathrm{f}_{\mathrm{k}}\right)\right|^{2}}{\mathrm{G}_{\mathrm{p}}\left(\mathrm{f}_{\mathrm{k}}\right) \mathrm{G}_{\mathrm{v}}\left(\mathrm{f}_{\mathrm{k}}\right)}
$$

where:

$G_{p}, G_{v}$ - spectral density values of the signals $p\left(t_{n}\right), v\left(t_{n}\right)$, respectively

$\mathrm{G}_{\mathrm{pv}} \quad$ - mutual spectral density value of the signals $\mathrm{p}\left(\mathrm{t}_{\mathrm{n}}\right)$, $\mathrm{v}\left(\mathrm{t}_{\mathrm{n}}\right)$.

The coherence function takes values from the interval :

$$
0 \leq \gamma_{\mathrm{pv}}^{2}\left(\mathrm{f}_{\mathrm{k}}\right) \leq 1
$$

Zero - value means that there is no casual relation between the signals, and one-value - that the signals come from the same source.

The tests were commenced from the measurements of main engine vibrations and underwater noise resulting from the vibrations. Next the tests were performed of the electric generating sets and remaining devices installed onboard and which influence ship acoustic field structure.

The assumed measurement method makes it possible to find the components of power density spectrum which uniquely characterize the tested ship.

Vibrations of ship propulsion systems and electric generating sets were measured by means of piezo-electric acceleration indicators which were fixed to ship hull and engine seatings by using screw joints, in order to make transmission characteristics as broad as possible. The accelerometers were screwed to the under-frame of the engine in the places of its connection with the frame. Another accelerometers were screwed to the ship's hull directly below the former accelerometers. The so selected fixing places of accelerometers made it possible to investigate vibration energy resulting from work of engines and transferred directly to the under-frame and further through the ship's hull to surrounding water.

Schematic arrangement plan of the measurement points is presented in Fig. 2.

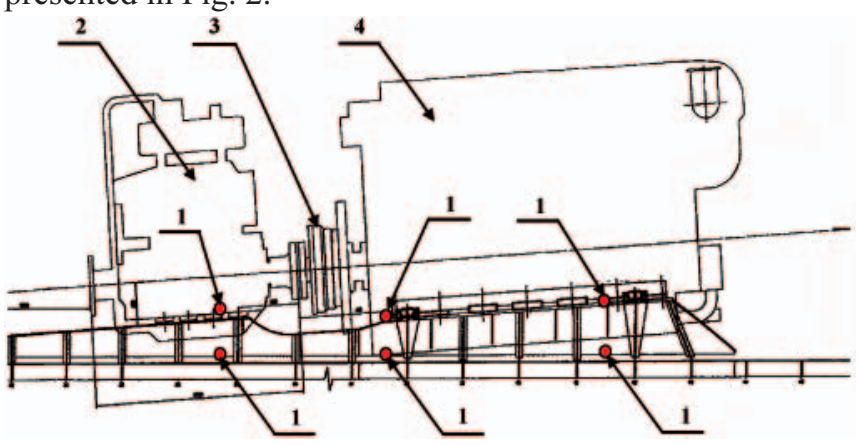

Fig. 2. Schematic arrangement plan of the measurement points

Notation: 1 - accelerometers, $\mathbf{2}$ - reduction gear, $\mathbf{3}$ - coupling (of elastic connection with main engine and rigid one with shafting), 4 - 6ATL 25R engine.

The ship's propulsion system is consisted of two 6ATL 25R Cegielski - Sulzer non-reversible main engines, two four-blade $\mathrm{CP}$ propellers and a reduction gear. On the ship two shaft- lines supported by three slide bearing each, are installed.

\section{RESULTS OF THE TESTS OF THE RIGHT MAIN ENGINE RUNNING AT 750 RPM SPEED}

The tests were performed for both propulsion systems at the rotational speed of main engines : 600, 750, 800, 850 [rpm]. To record and process signals the following instrumentation produced by B \&K firm was applied : the 8101 measuring hydrophones, 2626, 2628 and 2636 measuring amplifiers, 2308 $\mathrm{X}-\mathrm{Y}$ recorder, and 2145 two-channel frequency analyzer. The analyzer makes it possible to measure vibrations, acoustic pressure and rotational speed as well as to process recorded signals. Operational correctness of the vibration measuring system was checked in advance by means of the 4294 calibrating exciter. The exciter constitutes a small-size source of vibration intended for the field calibration of measuring systems, having the rms value of signal constant, equal to $10\left[\mathrm{mms}^{-2}\right] \pm 3[\%]$ at $159.2[\mathrm{~Hz}](1000[\mathrm{rad} / \mathrm{s}])$. And, operational correctness of the noise measuring system was checked by using the 4223 hydrophone calibrator. It serves for calibrating the hydrophones together with the measuring system in field conditions. The reference signal is equal to $151[\mathrm{~dB}] \div 166[\mathrm{~dB}]$ against $1[\mu \mathrm{Pa}]$ at $250[\mathrm{~Hz}]$; and the calibration accuracy: $\pm 0.3[\mathrm{~dB}]$.

In this paper - for the reason of a vast amount of data obtained from the measurements - are included only those dealing with the tests of the right main engine at $750 \mathrm{rpm}$ as well as of both main engines at $600 \mathrm{rpm}$.

In Fig. 3 is presented the spectrum of acoustic signals and vibrations elaborated in the frequency band up to $100[\mathrm{~Hz}]$ at $0.25[\mathrm{~Hz}]$ resolution.

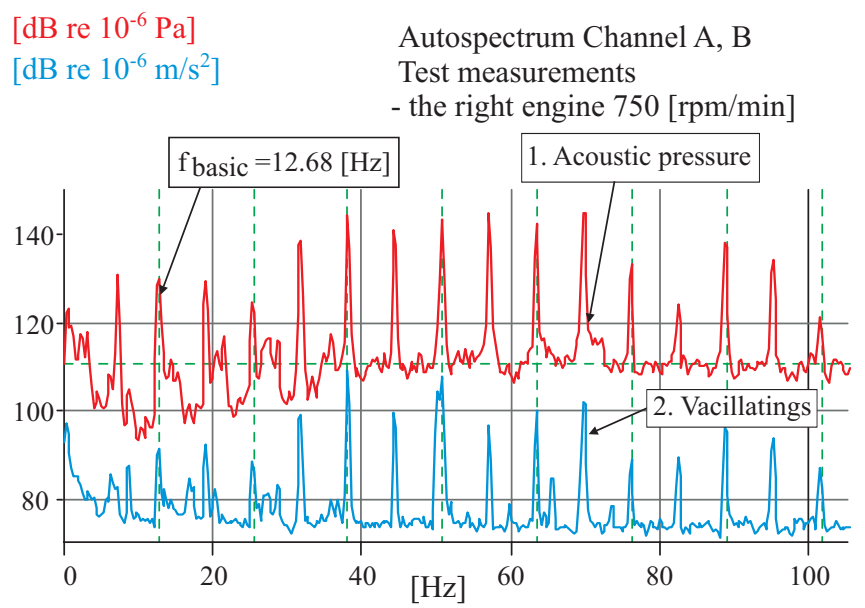

Fig. 3. Spectrum of underwater noise and vibrations. Notation: 1 - Acoustic pressure measured under the ship's hull in the place of main engine seating, 2 - Vibrations measured at the seating of the right main engine.

In the figure the upper spectrum represents changes of acoustic pressure in function of its frequency. The signals were recorded by the acoustic indicator placed under the ship in the distance of about $3.5 \mathrm{~m}$ from the hull. Changes of vibration acceleration in function of its frequency are presented in black colour. The vibrations were recorded at the engine seating. Additionally is showed the fundamental frequency of $12.68[\mathrm{~Hz}]$ resulting from main engine rotation, as well as the subsequent harmonics. In the spectra can be observed the characteristic components which appeared at the same frequencies. To settle similarity of the recorded signals the coherence function showed in Fig. 4, was determined. On the function's diagram several characteristic components of the function, whose values are close to 1 , can be observed.

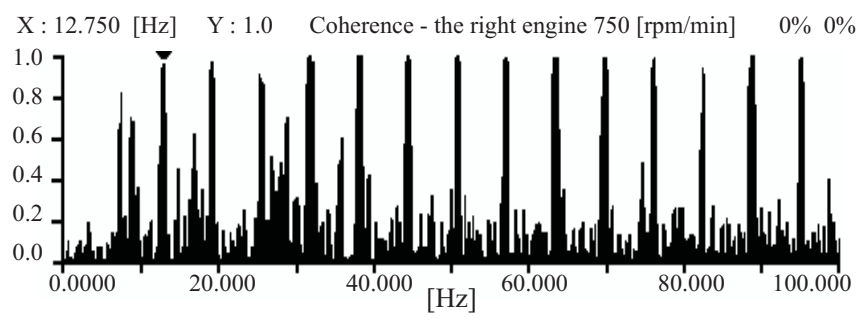

Fig. 4. Coherence function of underwater noise and vibrations 
Determination of accurate value of rotational speed of the main engine made it possible to calculate frequencies associated with rotations of shaft-line, screw propeller and firings occurring in the main engine. The frequencies together with the subsequent harmonics are presented in Tab. 1.

Tab.1. Vibration frequencies and subsequent harmonics of the engine calculated by using its real rotational speed.

\begin{tabular}{|c|c|c|c|}
\hline $\begin{array}{l}\text { Source of } \\
\text { vibration }\end{array}$ & \multicolumn{2}{|c|}{$\begin{array}{c}\text { Vibration frequency } \\
{[\mathrm{Hz}]}\end{array}$} & $\begin{array}{c}\text { Subsequent } \\
\text { harmonics } \\
{[\mathrm{Hz}]}\end{array}$ \\
\hline $\begin{array}{c}\text { Unbalanced } \\
\text { moving } \\
\text { parts } \\
\text { of main } \\
\text { engine }\end{array}$ & $\mathrm{f}_{\mathrm{n}}=\mathrm{kf} \mathrm{o}_{\mathrm{o}}$ & 12.68 & $\begin{array}{c}25.36,38.04 \\
50.72\end{array}$ \\
\hline $\begin{array}{l}\text { Fuel violent } \\
\text { combustion } \\
\text { in cylinders }\end{array}$ & $\mathrm{f}_{\mathrm{z}}=\mathrm{kz}_{\mathrm{c}} \mathrm{f}_{\mathrm{o}} \mathrm{s}$ & $\begin{array}{l}6.34,12.68 \\
19.02,5.36 \\
31.70,8.04\end{array}$ & $\begin{array}{c}44.38,50.72, \\
57.06,63.40, \\
69.74,76.08, \\
82.42,88.76, \\
95.10\end{array}$ \\
\hline $\begin{array}{l}\text { Unbalance } \\
\text { of shaft-line }\end{array}$ & $\mathrm{f}_{\mathrm{w}}=\frac{\mathrm{kf}_{\mathrm{o}}}{2 \cdot 1.77}$ & 3.58 & $\begin{array}{c}7.16,10.74 \\
14.32\end{array}$ \\
\hline $\begin{array}{c}\text { Unbalance } \\
\text { of screw } \\
\text { propeller }\end{array}$ & $\mathrm{f}_{\mathrm{s}}=4 \frac{\mathrm{kf}_{\mathrm{o}}}{1.77}$ & 28.66 & $57.32,85.98$ \\
\hline
\end{tabular}

\section{Notation:}

$\mathrm{k}=1,2,3, \ldots, \mathrm{n}$, subsequent harmonics

$f_{n}$ - main engine unbalance frequency

$f_{z}^{n}$ - frequencies of firing in main engine cylinders

$\mathrm{f}_{\mathrm{o}}$ - fundamental frequency $\mathrm{f}_{\mathrm{o}}=\frac{\mathrm{n}}{60}$

$\mathrm{n}$ - rotational speed [rpm]

$f_{w}$ - shaft-line unbalance frequency

$\mathrm{f}_{\mathrm{s}}^{\mathrm{w}}$ - propeller unbalance frequency

$\mathrm{s}$ - stroke factor $(0.5$ - for 4 -stroke engine $)$

$\mathrm{Z}_{\mathrm{c}}$ - number of cylinders

1.77 - reduction ratio of transmission gear.

Results of identification of wave frequencies associated with combustion processes occurring in engine cylinders, as well as with shaft-line and propeller operation are presented in Tab. 2 and 3.

Tab.2. List of frequencies associated with combustion processes occurring in main engine cylinders

\begin{tabular}{|c|c|c|c|c|c|}
\hline \multicolumn{2}{|c|}{ Frequency $[\mathrm{Hz}]$} & Coherence & \multicolumn{2}{c|}{ Frequency $[\mathrm{Hz}]$} & Coherence \\
\hline $\mathbf{1}$ & $\mathbf{2}$ & $\mathbf{3}$ & $\mathbf{1}$ & $\mathbf{2}$ & $\mathbf{3}$ \\
\hline 12.68 & 12.75 & 1 & 57.06 & 57.00 & 1 \\
\hline 19.02 & 19.00 & 1 & 63.40 & 63.25 & 1 \\
\hline 25.36 & 25.25 & 0.9 & 69.74. & 69.50 & 1 \\
\hline 31.70 & 31.75 & 1 & 76.08 & 76.00 & 1 \\
\hline 38.04 & 38.00 & 1 & 82.42 & 82.25 & 0.9 \\
\hline 44.38 & 44.25 & 1 & 88.76 & 88.50 & 1 \\
\hline 50.27 & 50.50 & 1 & 95.10 & 95.00 & 1 \\
\hline
\end{tabular}

Tab. 3. List of frequencies associated with shaft-line and screw propeller rotation.

\begin{tabular}{|c|c|c|c|c|c|}
\hline \multicolumn{3}{|c|}{ Shaft-line } & \multicolumn{3}{c|}{ Screw propeller } \\
\hline \multicolumn{2}{|c|}{ Frequency [Hz] } & Coherence & \multicolumn{2}{c|}{ Frequency [Hz] } & Coherence \\
\hline $\mathbf{1}$ & $\mathbf{2}$ & $\mathbf{3}$ & $\mathbf{1}$ & $\mathbf{2}$ & $\mathbf{3}$ \\
\hline 7.16 & 7.25 & 0.8 & 28.66 & 28.50 & 0.7 \\
\hline
\end{tabular}

\section{Notation:}

1 - values of vibration frequencies calculated on the basis of the real rotational speed of the main engine (equal to $760,8[\mathrm{rpm}])$,

2 - values of vibration frequencies taken from the spectrum shown in Fig. 3.

3 - values of the coherence function of underwater noise and vibrations.

Basing on the tests performed on the right main engine running at the rotational speed of $750[\mathrm{rpm}]$ one can evidence the relation occurring between vibrations of the ship devices and underwater noise.

In Fig. 3 the spectra of vibration accelerations and acoustic pressure are presented. In both diagrams distinct components of the same frequencies, resulting from operation of the main engine, rotating shaft-line and screw propeller, can be observed. The professional PULSE LABSHOP software of B\&K firm, used for signal processing, made it possible to exactly determine the frequency resulting from rotation of the main engine's shaft. On the basis of this frequency $(12.68[\mathrm{~Hz}])$ the real rotational speed $(760.8[\mathrm{rpm}])$ of the tested engine was determined during signal recording. Knowing values of spectral densities of acoustic pressure and vibrations one compared the signals by using the coherence function (Fig. 4). In this figure can be observed the characteristic components of values close to one, which unambiguously confirm the relation between vibrations generated by working engine, shaft-line and screw propeller and underwater noise.

The same testing method was used for the tests of main engines and auxiliary devices carried out at the remaining rotational speeds.

\section{RESULTS OF THE TESTS OF BOTH MAIN ENGINES RUNNING AT 2*600 RPM SPEED}

Identification of structure of ship acoustic field generated by two main engines of similar masses and running at almost the same rotational speed, is a complex issue. The summed up vibration energy resulting from work of the engines is transferred through ship structural elements to surrounding water and recorded by accelerometers placed at particular engines, that additionally makes their identification more difficult. The spectrum obtained from the tests is presented in Fig. 5.

Autospectrum Channel A, B

Test measurements - the left and right engine $600[\mathrm{rpm} / \mathrm{min}]$ $\left[\mathrm{dB}\right.$ re $\left.10^{-6} \mathrm{~Pa}\right]$

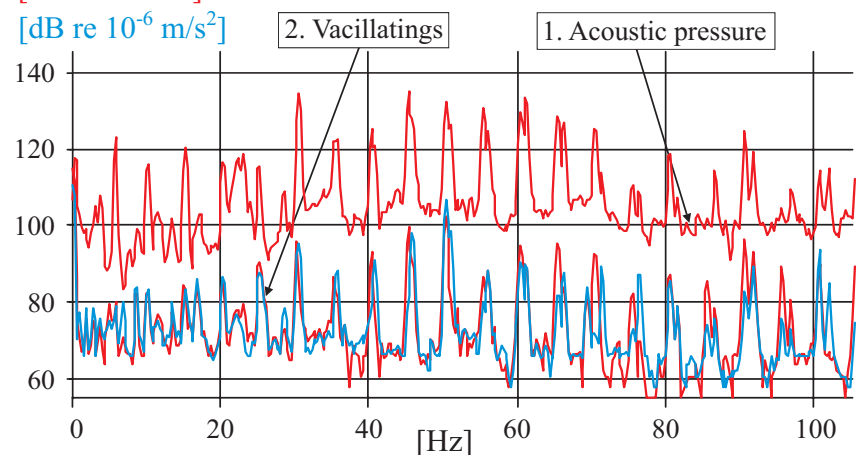

Fig.5. Spectrum of underwater noise and vibrations of the left and right main engine running at the rotational speed $n=2 * 600$ [rpm]. Notation: 1 - Acoustic pressure measured under the ship's hull in the place of main engine seating, 2 - Vibrations of the left and right main engine measured at their seatings.

In the acoustic pressure spectrum, the characteristic components generated by the considered propulsion systems, 
can be observed. It can be seen that in the spectrum over $30[\mathrm{~Hz}]$ frequency appear double stripes which are more and more distinct along with frequency increasing. The phenomenon resulted from that the investigated wave sources operated at different rotational speeds (of 610.8 [rpm] - the left engine and of 602.4 [rpm] - the right engine). The fundamental frequencies of the engines are contained within $0.25[\mathrm{~Hz}]$ band width of the filter used for signal processing (i.e. $10.18[\mathrm{~Hz}]-$ the fundamental frequency of the left engine and $10.04[\mathrm{~Hz}]$ - that of the right engine). The subsequent harmonics are displaced to each other by more than $0.25[\mathrm{~Hz}]$ that can be observed in the presented spectrum (e.g. $61.08[\mathrm{~Hz}]$ - the harmonic associated with operation of the left engine, $60.24[\mathrm{~Hz}]$ - that associated with operation of the right engine).

From the performed tests it results that in the underwater noise of the frequency band up to $30[\mathrm{~Hz}]$ the characteristic components generated by the left and right engine, can be identified. To this end was performed the analysis of the signals in the frequency band from $3.5[\mathrm{~Hz}]$ to $28.5[\mathrm{~Hz}]$ with $31.25[\mathrm{mHz}]$ resolution, presented in Fig. 6 where the frequencies associated with operation of the right engine are marked red and those associated with the left engine - blue.

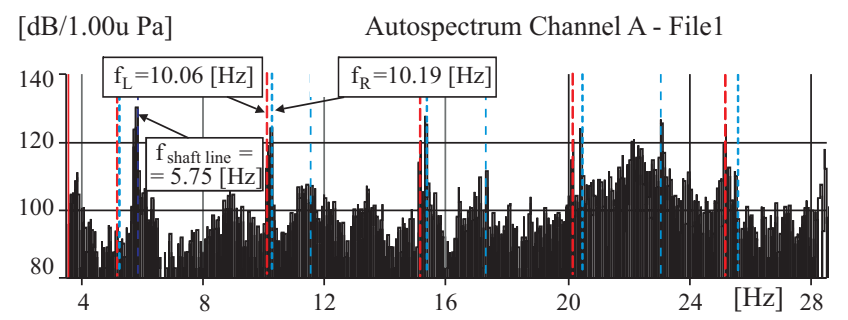

Fig. 6. Underwater noise spectrum recorded on the ship in the mooring stage at the rotational speed of the main engines $n=2 * 600$ [rpm]

The fundamental frequencies of running main engines and shaft-lines, obtained from the noise spectrum are as follows:

$\rightarrow$ resulting from unbalanced moving parts of the right engine $-\mathrm{f}_{\mathrm{R}}=10.06[\mathrm{~Hz}]$

$\Rightarrow$ resulting from unbalanced moving parts of the left engine $-\mathrm{f}_{\mathrm{L}}=10.19[\mathrm{~Hz}]$

$\Rightarrow$ resulting from unbalance of the shaft-line of the right propulsion system $-\mathrm{f}_{\text {linii wałów }}=5.69[\mathrm{~Hz}]$

$\rightarrow$ resulting from unbalance of the shaft-line of left propulsion system - $\mathrm{f}_{\text {shaft line }}=5.75[\mathrm{~Hz}]$.

To perform identification of vibration spectrum against underwater noise spectrum the above described coherence function was elaborated. The obtained results of the identification of acoustic waves is presented in Tab. 4 and 5 .

Basing on the tests performed on the main engines running at the rotational speed $\mathrm{n}=2 * 600[\mathrm{rpm}]$ one can evidence the relation occurring between vibrations and underwater noise. It is also possible to identify sources of the waves in surrounding water.

Values of the coherence function containing frequencies associated with combustion processes occurring in cylinders of main engines, are contained within the interval from 0.5 to 1 - for the right engine. The values unambiguously confirm the relation between vibrations and underwater noise. Similar values for the left engine are contained within the interval from 0.2 to 1 . The following values : 0.4 for $10.25[\mathrm{~Hz}]$, frequency, 0.3 for $20[\mathrm{~Hz}], 0.3$ for $50.25[\mathrm{~Hz}]$ and 0.2 for $85[\mathrm{~Hz}]$ did not confirm satisfactorily occurrence of a relation between that signals. The remaining values of the coherence function contained in the interval from 0.5 to 1 did confirm the relation. The frequencies associated with running the shaft-lines and screw propeller were determined from real values of rotational speed of main engines. The results are presented in Tab. 4. The obtained values of the coherence function, associated with vibrations generated by the shaft-lines and those with acoustic pressure are as follows : 0.8 for the left propulsion system and 0.9 for the right one. Similar values associated with running screw propellers are for these propulsion systems : 0.6 and 0.7 , respectively. They also confirm occurrence of the relation between vibrations and noise.

Tab. 4. List of frequencies associated with combustion processes occurring in cylinders of main engines

\begin{tabular}{|c|c|c|c|c|c|}
\hline \multicolumn{7}{|c|}{ Frequency [Hz] } & Coherence & \multicolumn{2}{c|}{ Frequency [Hz] } & Coherence \\
\hline $\mathbf{1}$ & $\mathbf{2}$ & $\mathbf{3}$ & $\mathbf{1}$ & $\mathbf{2}$ & $\mathbf{3}$ \\
\hline \multicolumn{7}{|c|}{ Right engine } \\
\hline 10.19 & 10.25 & 0.9 & 56.05 & 56.00 & 1 \\
\hline 15.29 & 15.50 & 0.9 & 61.14 & 60.25 & 1 \\
\hline 20.38 & 20.50 & 0.7 & 66.24 & 66.25 & 1 \\
\hline 25.48 & 25.25 & 0.5 & 71.33 & 71.25 & 0.9 \\
\hline 30.57 & 30.75 & 1 & 76.43 & 76.25 & 0.9 \\
\hline 35.67 & 35.75 & 1 & 81.52 & 81.50 & 1 \\
\hline 40.76 & 40.75 & 0.9 & 86.61 & 86.75 & 0.9 \\
\hline 45.86 & 46.00 & 1 & 91.71 & 91.75 & 0.9 \\
\hline 50.95 & 51.00 & 1 & 96.81 & 96.75 & 0.8 \\
\hline \multicolumn{7}{|c|}{ Left engine } \\
\hline $\mathbf{1}$ & $\mathbf{2}$ & $\mathbf{3}$ & $\mathbf{1}$ & $\mathbf{2}$ & $\mathbf{3}$ \\
\hline 10.06 & 10.25 & 0.4 & 55.33 & 55.25 & 1 \\
\hline 15.09 & 15.00 & 0.5 & 60.36 & 60.25 & 1 \\
\hline 20.12 & 20.00 & 0.3 & 65.39 & 65.25 & 0.9 \\
\hline 25.15 & 25.00 & 0.9 & 70.42 & 70.25 & 1 \\
\hline 30.18 & 30.00 & 1 & 75.45 & 75.50 & 0.8 \\
\hline 35.21 & 35.25 & 0.9 & 80.48 & 80.50 & 1 \\
\hline 40.24 & 40.25 & 1 & 85.51 & 85.50 & 0.2 \\
\hline 45.27 & 45.25 & 1 & 90.54 & 90.50 & 1 \\
\hline 50.30 & 50.25 & 0.3 & 95.57 & 95.50 & 0.8 \\
\hline
\end{tabular}

Tab. 5. List of frequencies associated with rotating shaft-lines and screw propeller

\begin{tabular}{|c|c|c|c|c|c|}
\hline \multicolumn{5}{|c|}{ Shaft-line } & \multicolumn{3}{|c|}{ Screw propeller } \\
\hline \multicolumn{7}{|c|}{ Frequency [Hz] } & Coherence & \multicolumn{2}{|c|}{ Frequency [Hz] } & Coherence \\
\hline $\mathbf{1}$ & $\mathbf{2}$ & $\mathbf{3}$ & $\mathbf{1}$ & $\mathbf{2}$ & $\mathbf{3}$ \\
\hline \multicolumn{7}{|c|}{ Left engine } \\
\hline 5.75 & 5.75 & 0.8 & 23.02 & 23.00 & 0.6 \\
\hline \multicolumn{7}{|c|}{ Right engine } \\
\hline 5.68 & 5.75 & 0.9 & 22.73 & 22.50 & 0.7 \\
\hline
\end{tabular}

\section{TESTS OF ELECTRIC GENERATING SETS}

During the ship's mooring tests measurements of vibrations and acoustic pressure for four electric generating sets were performed. Results of the acoustic measurements were recorded by using the hydrophone located under the ship's hull in the place of seating a given generator. Vibrations were measured at the seating frame as well as the hull frames under a given electric generating set.

For signal recording the $2145 \mathrm{~B} \& \mathrm{~K}$ analyzer fitted with a software for elaborating the spectrum of $200[\mathrm{~Hz}]$ constant band width at $0.5[\mathrm{~Hz}]$ resolution, was applied. The so recorded results were transmitted to an analyzing storing set. For further processing the signals the Microsoft Excel software was implemented. 
The spectrum of underwater noise and vibrations recorded at the main engine's seating and the ship's hull is presented in Fig. 7. To better visualize the spectra the obtained values of vibrations were damped by $20[\mathrm{~dB}]$.

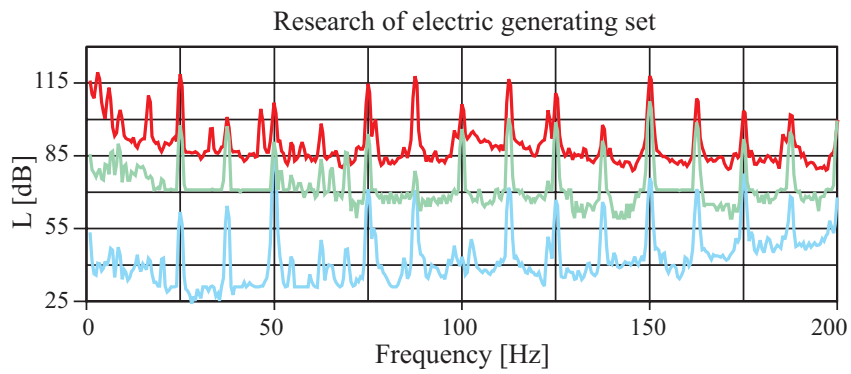

- Hydro-acoustic pressure recorded by the hydrophone placed under ship's hull in the area of the seating of electric generating set. Vibrations recorded at the seating of electric generating set. The signal damped by 20 [dB].

- Vibrations recorded at the ship's hull, under electric generating set. The signal damped by 20 [dB].

Fig. 7. Spectrum of underwater noise and vibrations of electric generating set

In the figure the upper spectrum marked red represents changes of acoustic pressure in function of its frequency. In green is presented the spectrum of vibrations recorded at the seating of electric generating set, and in black - the spectrum of vibrations recorded at the ship's hull.

In the spectra characteristic components occurring at the same frequencies can be observed, which leads to the conclusion that there is a relation between vibrations and underwater noise. The similarity between the obtained results was assessed by using the above described coherence function. In the function's diagram (Fig. 8 and 9) several stripes are observed whose values oscillate around one for the frequencies associated with operation of the tested electric generating set.

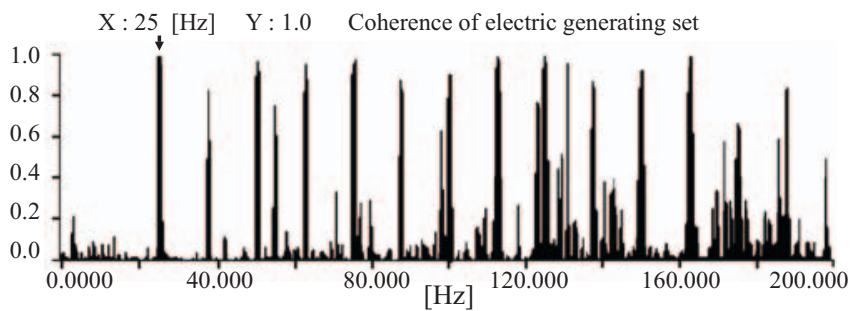

Fig. 8. Coherence function of underwater noise and vibrations of electric generating set; the vibrations were recorded at the seating of the set.

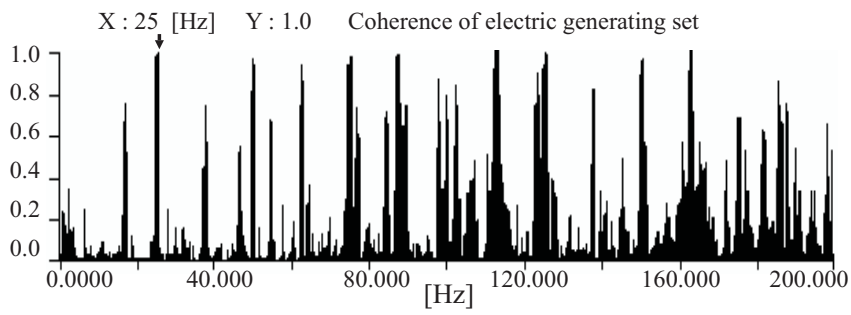

Fig. 9. Coherence function of underwater noise and vibrations of electric generating set; the vibrations were recorded at the ship's hull just under the set.

In Tab. 5 complete results obtained from the tests of the electric generating set no. 1 are presented. They contain values of hydro-acoustic pressure recorded by means of the hydrophone located under the ship's hull in the place of seating the electric generating set, as well as values of vibration velocity recorded at the engine's seating and ship's hull. The presented frequencies are associated with violent fuel combustion in cylinders. They were determined by using the same relations as in the case of the main engines' tests.
Tab. 5. Results obtained from the tests of the electric generating set no. 1

\begin{tabular}{|c|c|c|c|c|c|}
\hline \multicolumn{2}{|c|}{$\begin{array}{c}\text { Frequency } \\
{[\mathbf{H z}]}\end{array}$} & $\begin{array}{c}\text { Acoustic } \\
\text { pressure } \\
{[\mathbf{d B} \text { re 1 } \boldsymbol{\mu} \text { Pa] }}\end{array}$ & \multicolumn{2}{c|}{ Vibration velocity } & \multirow{2}{*}{ Coherence } \\
\cline { 5 - 6 } $\mathbf{1}$ & $\mathbf{2}$ & $\mathbf{3}$ & $\mathbf{4}]$ & {$[\mathbf{m m} / \mathbf{s}]$} & \\
\hline 25.00 & 119 & 4.8 & 80 & 1 & $\mathbf{5}$ \\
\hline 37.50 & 101 & 3.0 & 69 & 0.8 & 0.9 \\
\hline 50.00 & 107 & 1.1 & 537 & 1 & 1 \\
\hline 62.50 & 99 & 0.4 & 8 & 1 & 1 \\
\hline 75.00 & 115 & 1.1 & 76 & 1 & 1 \\
\hline 87.50 & 118 & 0.16 & 64 & 0.9 & 1 \\
\hline 100.00 & 106 & 1.0 & 2 & 1 & 0.9 \\
\hline 112.50 & 117 & 1.5 & 54 & 1 & 1 \\
\hline 125.00 & 111 & 1.1 & 28 & 1 & 1 \\
\hline 137.50 & 99 & 0.4 & 23 & 0.9 & 0.9 \\
\hline 150.00 & 118 & 2.4 & 67 & 1 & 1 \\
\hline 162.50 & 109 & 0.8 & 36 & 1 & 1 \\
\hline 175.00 & 104 & 0.3 & 68 & 0.7 & 0.9 \\
\hline 187.50 & 101 & 0.4 & 23 & 0.8 & 0.9 \\
\hline 200.00 & 100 & 0.7 & 20 & 0.9 & 1 \\
\hline
\end{tabular}

\section{Notation:}

1 - frequency of electric generating set

2 - acoustic pressure level measured under the ship's hull in the place of seating the generator

3 - vibration velocity values measured at the generator's seating

4 - vibration velocity values measured at the ship's hull in the place of seating the generator

5 - values of the coherence function between vibrations measured at the seating and hydro-acoustic pressure

6 - values of the coherence function between vibrations measured at the ship's hull and hydro-acoustic pressure.

On the basis of the tests performed on electric generating sets, can be demonstrated occurrence of relations between vibrations and underwater noise since the values of coherence function between vibrations measured at the ship's hull and hydro-acoustic pressure are comprised within the range from 0.9 to 1 , and for the vibrations measured at the engine's seating - within the range from 0.8 to 1 . These values unambiguously confirmed the relation occurring between vibrations and underwater noise. However to unambiguously identify the waves in the dynamic testing range may be very difficult as the energy of waves associated with operation of electric generating sets, transferred to water, is much smaller than that of the waves associated with operation of the main engines, screw propeller and shafting.

\section{RECAPITULATION OF THE MOORING TEST RESULTS AND DRAWN CONCLUSIONS}

In the mooring stage were performed the tests of two propulsion systems of the ship in question at the rotational speeds of the main engines : $600,750,800$ [rpm] as well as the separate tests of the right and left propulsion system 
operating at the speeds of $600,750,850$ [rpm], and additionally the tests of electric generating sets.

Results of the tests demonstrated that the identifying of hydro-acoustic waves associated with operation of those machines and devices is possible.

The statement of frequencies resulting from operation of main engines, obtained from the tests, is contained in Tab. 6.

Tab. 6. Frequencies resulting from operation of main engines at rotational speed values of 600, 750,800, 850 [rpm], obtained from the tests performed in the mooring stage

\begin{tabular}{|c|c|c|c|}
\hline \multirow{3}{*}{$\begin{array}{c}\text { Source } \\
\text { of } \\
\text { vibrations }\end{array}$} & \multicolumn{3}{|c|}{$\begin{array}{c}\text { Frequencies of propulsion system at main engine } \\
\text { rotational speed of : }[\mathrm{Hz}]\end{array}$} \\
\hline & $600[\mathrm{rpm}]$ & 750 [rpm] & 850 [rpm] \\
\hline & \multicolumn{3}{|c|}{ One propulsion system under operation } \\
\hline $\begin{array}{l}\text { Left main } \\
\text { engine } \\
\text { (right one } \\
\text { stopped) }\end{array}$ & $\begin{array}{c}10.25,15.25, \\
20.50,25.50, \\
30.75,35.25, \\
41.00,45.50, \\
51.00,56.25, \\
61.00,25.00, \\
66.50,71.50, \\
75.75,81.75, \\
87.00,92.25, \\
97.25 .\end{array}$ & $\begin{array}{c}12.50,18.75, \\
24.75,31.00, \\
37.75,43.50, \\
49.75,56.00, \\
62.25,68.25, \\
74.50,80.75, \\
87.00,93.25, \\
99.50 .\end{array}$ & $\begin{array}{l}14.25,21.50, \\
28.75,36.00, \\
43.25,50.25, \\
57.50,64.75, \\
72.00,79.00, \\
86.25,93.50\end{array}$ \\
\hline $\begin{array}{c}\text { Right } \\
\text { main } \\
\text { engine } \\
\text { (left one } \\
\text { stopped) }\end{array}$ & $\begin{array}{l}10.25,15.55, \\
20.50,25.75, \\
31.00,36.00, \\
41.25,46.50, \\
51.50,56.75, \\
61.00,75,67, \\
72.25,77.25, \\
82.50,87.50, \\
92.75,98.00\end{array}$ & $\begin{array}{l}12.75,19.00, \\
25.25,31.75, \\
38.00,44.25, \\
50.50,57.00, \\
63.25,69.50, \\
76.00,82.25, \\
88.50,95.00\end{array}$ & $\begin{array}{c}14.25,21.50, \\
28.50,35.75,43, \\
50,57.25,64.50, \\
71.50,78.75, \\
85.75,93.00\end{array}$ \\
\hline \multicolumn{4}{|c|}{ Two propulsion systems under operation } \\
\hline $\begin{array}{l}\text { Main } \\
\text { engine }\end{array}$ & $2 * 600[\mathrm{rpm}]$ & $2 * 750[\mathrm{rpm}]$ & $2 * 800[\mathrm{rpm}]$ \\
\hline Left one & $\begin{array}{l}10.25,15.50, \\
20.50,25.25, \\
30.75,35.75, \\
40.75,46.00, \\
51.00,56.00, \\
60.00,65.25, \\
71.25,76.25, \\
81.50,86.75, \\
91.75,96.75\end{array}$ & $\begin{array}{l}12.50,18.75, \\
25.00,31.25, \\
37.50,43.75, \\
50.25,56.50, \\
62.75,69.00, \\
75.25,81.50, \\
87.75,94.00\end{array}$ & $\begin{array}{c}13.00,19.75, \\
26.25,32.75, \\
39.25,45.75, \\
52.50,59.00 \\
65.50, \\
72.00,78.50 \\
85.25,91.75 \\
98.25\end{array}$ \\
\hline Right one & $\begin{array}{c}10.25,15.00, \\
20.00,25.00, \\
30.00,35.25, \\
40.25,45.00, \\
50.25,55.25,60 . \\
25,65.25,70.25, \\
75.50,80.50, \\
85.50,90.50, \\
95.50 .\end{array}$ & $\begin{array}{c}12.50,18.75, \\
25.00,31.5, \\
37.75,44.00, \\
50.50,56.75, \\
63.00,69.25, \\
75.50,81.75, \\
88.00,94.25\end{array}$ & $\begin{array}{c}13.25,19.75, \\
26.50,33.00, \\
39.50,46.25, \\
52.75,59.50 \\
66.00 \\
72.50,79.25, \\
85.50,92.50 \\
99.00\end{array}$ \\
\hline
\end{tabular}

On the basis of the rotational speeds of main engines basic frequencies associated with rotation of screw propeller and shafting were determined.

Knowing frequencies of the tested system as well as those associated with operation of electric generating sets one is able to identify the waves associated with operation of the propulsion system, which propagate in surrounding water.

From the above presented theoretical relationships it is possible to calculate frequencies of hydro-acoustic waves for all setting ranges of the propulsion systems in the frequency band up to $100[\mathrm{~Hz}]$. Such calculations were performed for the rotational speed values of main engines at which the ship in question usually operates.

The statement of the so calculated wave frequencies of the systems is given in Tab. 7 in which the frequencies resulting from operation of electric generating sets are also included. It can be expected that the waves of those frequencies will propagate in surrounding water during measurements to be carried out on the ship in motion.

Tab. 7. Frequencies resulting from operation of propulsion systems and electric generating sets, calculated by using theoretical relationships

\begin{tabular}{|c|c|c|c|c|}
\hline \multirow{2}{*}{$\begin{array}{c}\text { Source } \\
\text { of } \\
\text { vibrations }\end{array}$} & \multicolumn{4}{|c|}{$\begin{array}{l}\text { Frequencies of propulsion system at main engine } \\
\text { rotational speed values of : }[\mathrm{Hz}]\end{array}$} \\
\hline & $600[\mathrm{rpm}]$ & $750[\mathrm{rpm}]$ & 850 [rpm] & $950[\mathrm{rpm}]$ \\
\hline $\begin{array}{c}\text { Main } \\
\text { engines }\end{array}$ & $\begin{array}{c}5.00,10.00, \\
15.00,20.00, \\
25.00,30.00, \\
35.00,40.00, \\
45.00,50.00, \\
55.00,60.00, \\
65.00,70.00, \\
75.00,80.00, \\
85.00,90.00, \\
100.00 .\end{array}$ & $\begin{array}{c}6.25,12.50 \\
18.75,24.75 \\
31.00,37.25 \\
43.50,49.75, \\
56.00,62.25, \\
68.25,74.50 \\
80.75,93.25, \\
99.50 .\end{array}$ & $\begin{array}{c}7.00,14.25 \\
21.25,28.25 \\
34.50,42.50 \\
49.50,56.50 \\
63.75,70.75 \\
78.00,85,92 \\
99.00\end{array}$ & $\begin{array}{c}8.00, \\
15.75, \\
23.75, \\
31.50, \\
39.50, \\
47.50, \\
55.50, \\
63.25, \\
71.25, \\
79.25, \\
87.00, \\
95.00\end{array}$ \\
\hline $\begin{array}{c}\text { Screw } \\
\text { propeller }\end{array}$ & $\begin{array}{c}5.75,11.25, \\
17.00,22.5, \\
28.25,33.75 \\
39.50,45.25, \\
50.75,56.50 \\
62.25,67.75 \\
73.50,79.00 \\
84.75,93.25 \\
96.00 .\end{array}$ & $\begin{array}{c}7.00,14.00, \\
21.25,28.25, \\
35.25,42.25, \\
49.50,56.50, \\
63.50,70.50, \\
77.75,84.75, \\
91.75 .\end{array}$ & $\begin{array}{c}8.00,16.00, \\
24.00,32.00, \\
40.00,48.00, \\
56.00,64.00, \\
72.00,80.00, \\
88.00,96.00\end{array}$ & $\begin{array}{c}9.00, \\
18.00, \\
26.75, \\
35.75, \\
44.75, \\
53.75, \\
62.75, \\
71.50, \\
80.50, \\
89.50, \\
98.50\end{array}$ \\
\hline Shafting & $\begin{array}{l}2.75,5.75 \\
8.50,11.25 \\
14.25\end{array}$ & $\begin{array}{c}3.50,7.00 \\
10.50,14.00 \\
17.50,21.25\end{array}$ & $\begin{array}{c}4.00,8.00 \\
12.00,16.00 \\
20.00,25.00 \\
29.00\end{array}$ & $\begin{array}{l}4.50, \\
9.00, \\
13.50, \\
18.00 \\
22.50 \\
26.75\end{array}$ \\
\hline $\begin{array}{c}\text { Electric } \\
\text { generating } \\
\text { set }\end{array}$ & \multicolumn{4}{|c|}{$\begin{array}{c}12.50,25.00,37.50,50.00,62.50,75.00,87.50 \\
100.00,112.50,125.00,137.50,150.00,162.50 \\
175.00,187.50,200.00\end{array}$} \\
\hline
\end{tabular}


In order to confirm the results obtained from the tests carried out in the mooring stage it would be necessary to perform series of similar tests (but of a much wider scope) on the ship in a dynamic testing stage.

Such stages are well adjusted to measuring and analyzing the underwater noise of ships in motion as well as to monitoring hydro-acoustic background. The acoustic methods applied to this aim are specially useful because of a very wide range of propagation of hydro-acoustic waves in surrounding water. For this reason it will be possible to early detect alien floating units during permanent monitoring the coastal water zone if only structure of acoustic noise field of own ships and acoustic background is known.

\section{BIBLIOGRAPHY}

1. Cempel Cz. : Applied vibro-acoustics (in Polish). State Scientific Publishing House (PWN), Warszawa 1989

2. Baranowska A Gloza I.: Identification of underwater disturbance sources with the use of coherence function (in Polish). Materiałs of 48th Open Seminar on Acoustics, Wrocław 2001.

3. Gloza I., Malinowski S. : Identification of ship's underwater noise sources in the coastal region, Hydroacoustics, Vol. 5/6, 2003.

4. Gloza I., Domagalski J., Malinowski S. : Identification of sources of ship's hydro-acoustic field in a close surrounding (in Polish). Materiałs of 49th Open Seminar on Acoustics, Warszawa-Stare Jabłonki 2002.
5. Grelowska G., Bittner P., Gloza I.: Experimental research on noise generated by ship in motion (in Polish). Materials of 9th Symposium on Hydroacoustics, Gdynia - Jurata, 1992.

6. Kozaczka E., Kiciński W., Nyszko G.: Identifying investigations of acoustic signals emitted to water (in Polish), Phase II, IV. Research reports, Gdynia 1995.

7. Urick R. J. : Principles of Underwater Sound. Mc Graw - Hill, New York 1975

\section{CONTACT WITH THE AUTHORS}

Prof. Eugeniusz Kozaczka

Faculty of Ocean Engineering and Ship Technology

Gdansk University of Technology

Narutowicza 11/12

80-952 Gdansk, POLAND

e-mail : kozaczka@pg.gda.pl

Grażyna Grelowska

Mechanic-Electric Faculty,

Polish Naval University

Śmidowicza 69

81-103 Gdynia, POLAND

e-mail : grelowska@amw.gdynia.pl

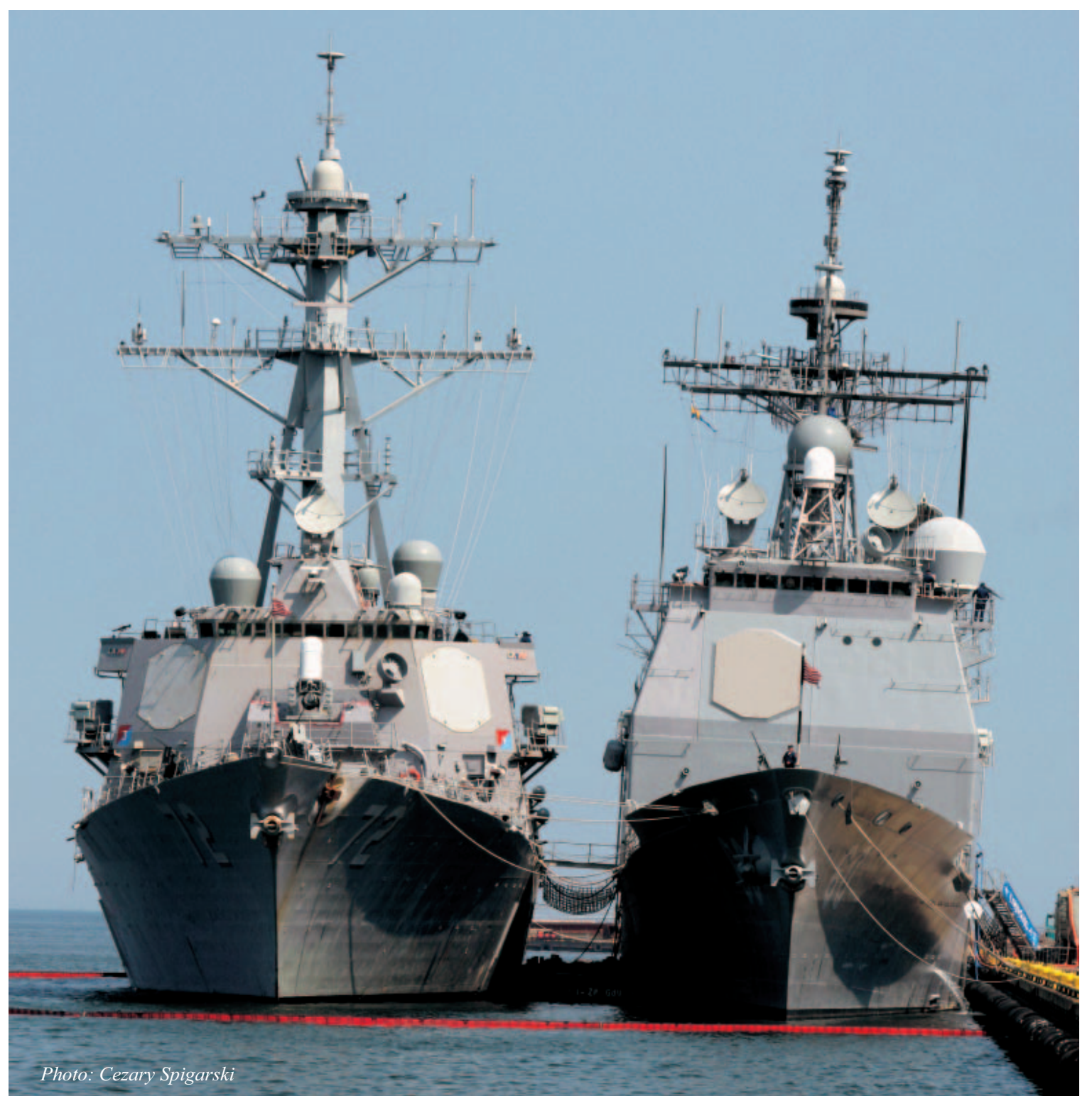

